\title{
Solitary nodule on the back: A diagnostic challenge on cytology
}

\author{
Manjari Kishore', Annu Nanda ${ }^{2}$, Deepak Kumar Singh ${ }^{3}$ \\ ${ }^{1}$ Specialist, ${ }^{2}$ Professor, ${ }^{3} \mathrm{HOD}$, Department of Pathology, ESI Hospital, Rohini, New Delhi, India
}

\begin{abstract}
Evaluation of a solitary lesion on the back can be a diagnostic challenge on cytology. However, based on the histological examination, differential diagnosis can be narrowed down, but still, sometimes, it becomes difficult to make a definitive diagnosis, even on biopsy findings. In such cases, the role of immunohistochemistry (IHC) becomes important. Herein, we present the case of a 49-year-old female who presented with a solitary nodule on the back, where fine-needle aspiration cytology followed by histology and IHC helped in making a definitive diagnosis of pseudolymphoma (lymphocytoma cutis), thereby differentiating it from lymphoma. This differentiation is crucial for early and accurate diagnosis, treatment, and prognosis of the patient.
\end{abstract}

Key words: Pseudolymphoma, Lymphoma, Cytology, Biopsy, Solitary nodule

$\mathrm{L}$

ymphocytoma cutis (LC), also termed as cutaneous lymphoid hyperplasia or Spiegler-Fendt sarcoid, results from various antigenic stimuli [1-4]. This entity is basically considered as a pseudolymphoma or collection of reactive polymorphic lymphoid cells where there is an accumulation of lymphocytes underneath the skin, thereby mimicking cutaneous lymphoma on histopathology [3-5]. Hence, it becomes important to establish the polymorphic nature of the lymphoid cells through immunohistochemistry (IHC) in these lesions.

Here, we describe the case of a 49-year-old-female patient who presented with a solitary nodular swelling at the back and was finally diagnosed with LC based on the histopathological and IHC evaluation. This diagnosis is of utmost importance keeping in view the management and prognosis of the patient.

\section{CASE REPORT}

A 49-year-old female presented to the hospital with a complaint of swelling on the left mid-back region. The swelling was mildly itchy, started 1 year back, and was slow growing. The patient did not have any history of any triggering agents such as an insect bite, drug intake, and vaccination.

On examination, a well-defined nodulocystic swelling was noted on the mid-back region toward the left side (Fig. 1a). The surface was smooth, however, the overlying skin showed mild discoloration. Clinically, the swelling was well-defined and

\section{Access this article online}

Received - 24 July 2020

Initial Review - 10 August 2020

Accepted - 16 October 2020

DOI: $10.32677 /$ IJCR.2020.v06.i10.015 considered benign in nature. General and systemic examination of the patient did not reveal any abnormality.

Complete blood count and other biochemical parameters were within normal limits. The patient was sent for fine-needle aspiration cytology (FNAC) with a provisional clinical diagnosis of epidermal inclusion cyst.

Fine-needle aspiration was done, and smears prepared were highly cellular, comprising many small to medium and round to oval-sized mononuclear cells with scant cytoplasm, round to oval nuclei, finely dispersed chromatin, and prominent nucleoli (Fig. 2a-b), also noted were elongated spindled and plasmacytoid looking cells with granular chromatin and a moderate amount of pale to dense cytoplasm seen singly scattered and few embedded in a pink matrix (Fig. 2c). The background showed a focal pink matrix, mixed inflammation, and occasional cystic macrophage admixed with blood. In view of cytological findings, a definitive diagnosis was difficult to be given, hence, the two possible differential diagnoses of adnexal neoplasm and the lymphoproliferative lesion were given. Subsequently, the excision of the lesion and its histopathological correlation was advised.

Complete excision of the lesion was done and sent for the histopathological examination. Fig. 1b shows the post-surgical picture of the lesion, with a scar mark. On gross examination, a single skin covered tissue measuring $2.8 \times 1.5 \times 1 \mathrm{~cm}$ was received (Fig. 1c). The external surface was partly skin covered and the cut surface showed gray-white areas along with focal yellow fatty areas. The specimen was cut into two bits and both the bits were sent for processing.

Correspondence to: Manjari Kishore, Specialist Pathology, Department of Pathology, Room No. 135, $1^{\text {st }}$ Floor, OPD Building, E.S.I.C. Hospital, Rohini, New Delhi, India. E-mail: drmanjarik@gmail.com

(C) 2020 Creative Commons Attribution-NonCommercial 4.0 International License (CC BY-NC-ND 4.0). 


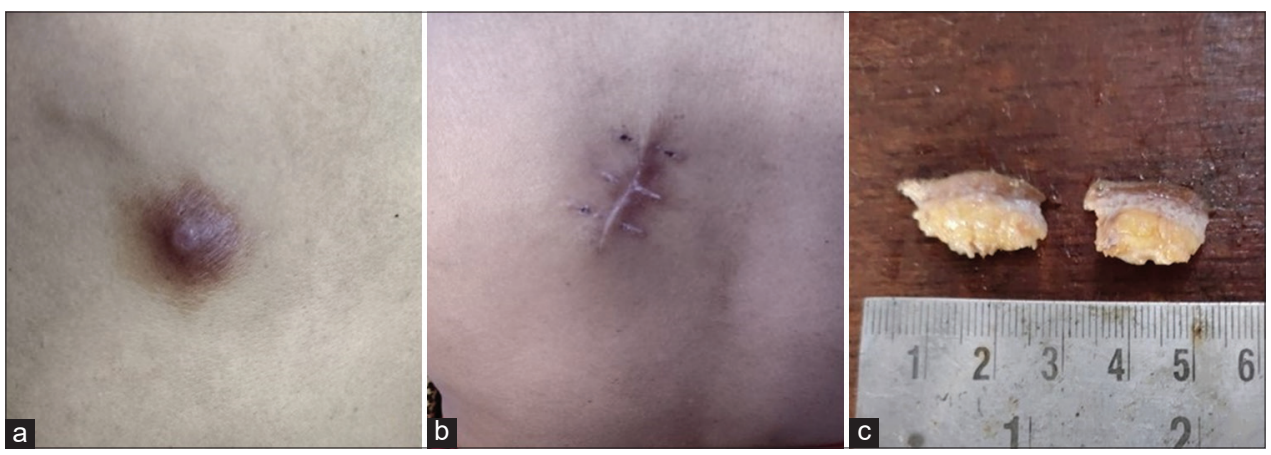

Figure 1: (a) Clinical image showing a well-defined firm swelling with mild discoloration on mid-back region toward left side; (b) post-excision image; (c) gross image of excised lesion showing a single skin covered tissue measuring $2.8 \times 1.5 \times 1 \mathrm{~cm}$

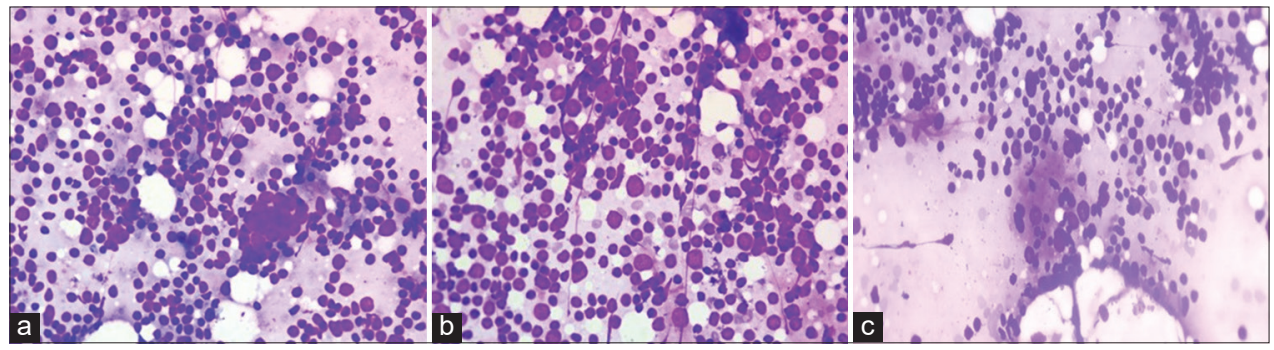

Figure 2: (a-c) Highly cellular smears, comprising many small to medium and round to oval-sized mononuclear cells with scant cytoplasm, round to oval nuclei, finely dispersed chromatin and prominent nucleoli (a-b, Giemsa, $\times 40)$. Also noted were elongated spindled and plasmacytoid looking cells with granular chromatin and moderate amount of pale to dense cytoplasm seen singly scattered and few embedded in pink matrix $(c$, Giemsa, $\times 40)$

Histopathological examination stained sections showed epidermis with its appendages and connective tissue stroma. The upper dermis was highly cellular with a clear zone of connective tissue separating the cells in the dermis from the epidermis (Fig. 3a). The cells were predominantly lymphocytes with few plasma cells, eosinophils, and histiocytes (Fig. 3b). These lymphoid cells were predominantly arranged in a dense sheet-like pattern; however, a focal follicular pattern was also noted (Fig. 3b). Although the upper dermis was majorly involved by these lymphoid cells, infiltration into the deeper dermis and subcutaneous tissue was also seen. Based on the clinical findings and histology, a final diagnosis of cutaneous lymphoid hyperplasia (LC) was made.

However, the important point was to differentiate this entity from cutaneous lymphoma, and hence, establishing the polyclonality of lymphocytes was required. IHC with LCA, CD3, and CD20 was done (Fig. 4a-d). The results showed positivity with all these antibodies, ruling out lymphoma and helped in achieving a final diagnosis of LC. The patient was given topical steroids and was advised to be on regular follow-up.

\section{DISCUSSION}

LC is also known as cutaneous pseudolymphoma, cutaneous lymphoid hyperplasia, or Spiegler-Fendt sarcoid [2-4]. It is a reactive process where there is a polyclonal T- or B-cell proliferation. It is a rare lesion presenting either as localized solitary lesion or in a disseminated form as multiple shiny plaques. This is usually noted in young adults with female preponderance. The disseminated form is also termed as military LC and is usually seen in elderly individuals [3-6]. This entity has a benign course and few other
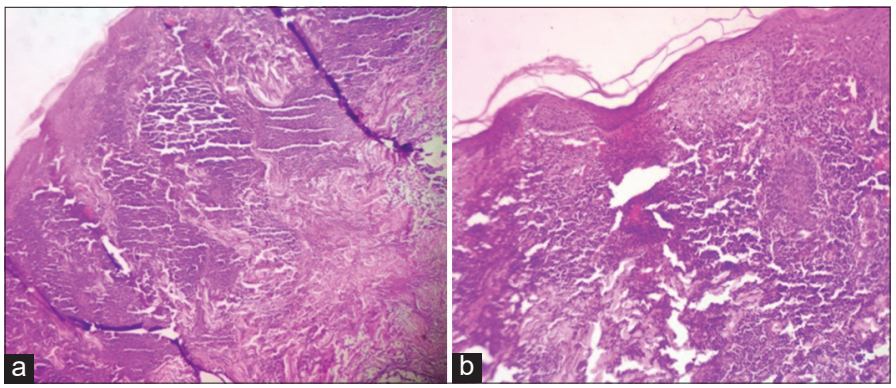

Figure 3: (a and b) H\&E stained sections showing unremarkable epidermis and highly cellular upper dermis with a clear zone of connective tissue separating the cells in dermis from epidermis (a-b, $\mathrm{H} \& \mathrm{E}, \times 20)$. These lymphoid cells were predominantly arranged in dense sheet-like pattern; however, focal follicular pattern was also noted $(b, H \& E, \times 40)$

terminologies which have been used to describe it are sarcoma cutis, lymphadenosis benigna cutis, and actinic reticuloid.

Considering the etiological factors, most cases of LC are idiopathic [4-7]. Second, reactive responses may be responsible for its causation such as skin disease (allergic reactions and dermatitis); some viral infections (herpes simplex and molluscum contagiosum); tattoo dyes, trauma, vaccination, drug reaction (antibiotics, anticonvulsant, anti-TNF $\alpha$ drugs, etc.), or even with Borrelia burgdorferi infection [5-8]. Although the common site involved is skin; LC may be noted in the eyes, tongue, parotid gland, larynx, GIT, lung, kidney, and breast [6-9].

In our case, it was noted in a middle-aged female patient who presented with a discrete, slightly pigmented swelling with itching in the left mid-back region. There was no definite etiological factor associated with its causation in our patient. 


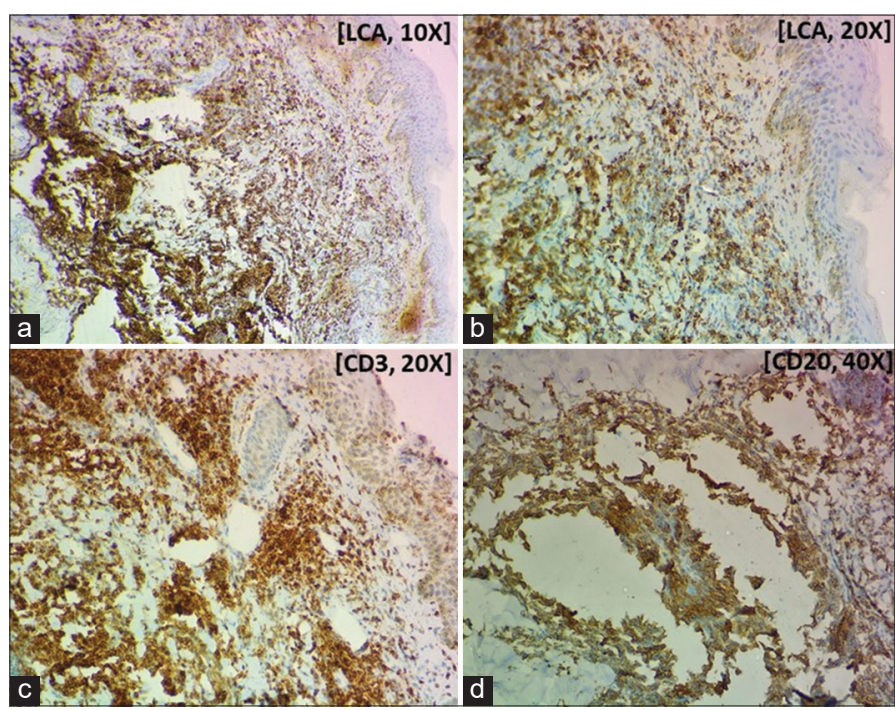

Figure 4: (a-d) IHC images showing positivity for LCA (a and b, $\times 10$ and $\times 20$, respectively), CD $3(c, \times 20)$, and CD20 $(d, \times 40)$

Usually, the cases of LC are diagnosed on histopathology, as reported in the literature. However, the patient came to us initially for FNAC and the smears showed high cellularity with two types of cell population; one type of cell was round to oval with scant cytoplasm, round to oval nuclei with fine dispersed chromatin. Also noted were spindle and plasmacytoid cells with a moderate amount of cytoplasm, embedded in the pink matrix material. The background showed inflammatory cells, few giant cells, and cystic macrophages. Based on the cytological features, the possibility of an adnexal lesion like pilomatricoma and second of the lymphoproliferative lesion was given, favoring benign process (LC) was given. However, excision and histopathological correlation were advised for a definitive diagnosis.

Histopathology helps in differentiating LC from a reactive cutaneous inflammation and lymphoma. Pseudolymphoma can be differentiated from a true lymphoma from these basic histological findings [8-11]. LC cases will show an admixture of B- and T-cells along with macrophages and dendritic cells. On histology, the lymphoid cells will show polymorphic lymphoid infiltrate with low-grade nuclear features. This reactive lymphoid population is noted as heavy top infiltrate; sparing the subcutis. In our case also, skin biopsy showed unremarkable epidermis and superficial and mid-dermis showing dense aggregates of mononuclear lymphoid cells, along with few follicles.

However, it becomes important to establish the polyclonality of these cells, as it becomes difficult to differentiate these lymphoid cells from lymphoma in a small biopsy [9-12]. Hence, IHC becomes important in making a definitive diagnosis. A mixture of B- and T-cell infiltration is more in favor of LC; hence, IHC positivity with a combination of B-cell marker such as CD20, CD 79a, CD10, CD45/LCA, and T-cell marker like $\mathrm{CD} 3$ can be used to establish the polyclonality and thereby giving a definitive diagnosis of LC. In our case, we applied IHC-LCA, CD20, and CD3, thereby ruling out the diagnosis of lymphoma. In fact, even if we get the follicular arrangement in the upper dermis, the possibility of follicular lymphoma should always be ruled out before making a definitive diagnosis.
Once a diagnosis of LC is made, management involves the complete surgical excision of the lesion along with the application of steroids post-surgery; other methods include cryosurgery, superficial radiotherapy, psoralen and ultraviolet A (PUVA), hydroxychloroquine, and photodynamic therapy [7-12]. If a definite cause like Borrelia infection is noted, it should be treated specifically for it. In our patient, complete surgical excision was done, and the patient was given topical steroids for local application.

Establishing a definitive diagnosis of LC is very important not only in terms of management purpose but also in long-term follow-up of the patient. It is important to note that, even it is a reactive process, follow-up of the patients is very crucial as there have been very rare cases of LC evolving into cutaneous lymphoma.

\section{CONCLUSION}

The present case highlights the importance of a very simple investigative process, that is, FNAC in directing a path for a provisional diagnosis of a pseudolymphomatous condition. This initial diagnosis must be backed up by the histopathological correlation along with the establishment of polyclonality in these reactive lymphoid cells. The differentiation of LC from true lymphoma is further important in planning the management and follow-up of the patient.

\section{REFERENCES}

1. De Oliveira EV, Badiale GB, Moraes MM. Lymphocytoma cutis-case report. An Bras Dermatol 2013;88:128-31.

2. Takeda H, Kaneko T, Harada K, Matsuzaki Y, Nakano H, Hanada K. Successful treatment of lymphadenosis benigna cutis with topical photodynamic therapy with delta-aminolevulinic acid. Dermatology 2005;211:264-6.

3. Ko CJ, Glusac EJ, Meyerle JH, Braunstein I. Cutaneous Pseudolymphoma. New York: Medscape; 2016.

4. May SA, Netto G, Domiati-Saad R, Kasper C. Cutaneous lymphoid hyperplasia and marginal zone B-cell lymphoma following vaccination. J Am Acad Dermatol 2005;53:512-6.

5. Wiesli P, Joos L, Galeazzi RL, Dummer R. Cutaneous pseudolymphoma associated with bromocriptine therapy. Clin Endocrinol 2000;53:656-7.

6. Marucci G, Sgarbanti E, Maestri A, Calandri C, Collina G. Gemcitabineassociated CD8+ CD30+ pseudolymphoma. Br J Dermatol 2001;145:650-2.

7. Lackey JN, Xia Y, Cho S, Sperling LC. Cutaneous lymphoid hyperplasia: A case report and brief review of the literature. Cutis 2007;79:445-8.

8. Moreno-Ramirez D, García-Escudero A, Ríos-Martín JJ, Herrera-Saval A, Camacho F. Cutaneous pseudolymphoma in association with molluscum contagiosum in an elderly patient. J Cutan Pathol 2003;30:473-5.

9. Leinweber B, Colli C, Chott A, Kerl H, Cerroni L. Differential diagnosis of cutaneous infiltrates of B lymphocytes with follicular growth pattern. Am J Dermatopathol 2004;26:4-13.

10. O'Neill J, Fien S, Zeitouni NC. ALA-PDT for the treatment of cutaneous pseudolymphoma: A case report. J Drugs Dermatol 2010;9:688-9.

11. Joseph D, Irukulla MM, Ahmed SF, Valiyaveettil D, Akram S. Radiotherapy in aggressive cutaneous pseudolymphoma: A case report and review of literature. Radiat Oncol J 2016;34:76-80.

12. Pacheco D, Travassos AR, De Almeida LS, Silva R, Filipe P. Solitary T-cell pseudolymphoma of the breast, treated by PUVA. Eur J Dermatol 2013;23:397-8.

Funding: None; Conflicts of Interest: None Stated.

How to cite this article: Kishore M, Nanda A, Singh DK. Solitary nodule on the back: A diagnostic challenge on cytology. Indian J Case Reports. 2020;6(10):591-593. 